\title{
O PROCESSO IMIGRATÓRIO DOS DECASSÉGUIS AO JAPÃO: COMO PLANEJAM SEUS PROJETOS DE VIDA
}

\author{
Renato Yoshio Arai, Mary Yoko Okamoto
}

Curso de Psicologia; Departamento de Psicologia Clínica; Universidade Estadual Paulista "Júlio de Mesquita Filho" - UNESP - Faculdade de Ciências e Letras - Assis. Fundação de Amparo à Pesquisa do Estado de São Paulo - FAPESP. E-mail: rya kab@hotmail.com

\section{RESUMO}

Com a imigração japonesa no inicio do século $X X$ ao Brasil se inicia, após algumas décadas o movimento decasségui, ou seja, a imigração de descendentes nipo-brasileiros ao Japão, que assim como seus antepassados, emigram com intuito de acumularem riquezas para uma melhor qualidade de vida. Esse processo imigratório ocorre há mais de três décadas e em seu auge, chegou a atingir em torno de 300.000 brasileiros no território japonês. Assim, o objetivo dessa pesquisa é averiguar como os decasséguis planejam seu futuro, isto é, constituem seus projetos de vida, a quais aspectos de vida estão atrelados e a qual país.

Palavras-chave: Brasil, imigração japonesa, Japão, movimento decasségui, projeto de vida.

\section{INTRODUÇÃO E OBJETIVO}

\subsection{A imigração japonesa}

Em 1908, aportava o navio japonês Kasato Maru no porto de Santos, trazendo o primeiro grupo de imigrantes japoneses, constituído de 781 pessoas, sendo que a maioria era de homens para o trabalho nas lavouras cafeeiras do Estado de São Paulo. Desta maneira se iniciou a imigração japonesa para o Brasil (OKAMOTO, 2007).

O governo japonês deu início a tal processo com a proposta de que aqui havia "árvores dos frutos de ouro" (OKAMOTO, 2007), para fortalecer a visão de enriquecimento rápido e fácil. Entretanto, os imigrantes se depararam com os problemas de adaptação principalmente devido às diferenças na alimentação e a falta de intérpretes que falassem a língua portuguesa.

Porém, tal enriquecimento não pôde ser concretizado, pois o ganho financeiro não era tão fácil e rápido quanto aquele divulgado e esperado. Com a derrota do Japão na II Guerra Mundial, a permanência definitiva no Brasil foi concretizada. Nesse período, muitos imigrantes iniciaram a aquisição de terras tornando-se pequenos proprietários rurais ou se agrupando em núcleos e formando pequenas cooperativas. Em 1952 encerra-se esse ciclo da imigração de japoneses ao Brasil. 


\subsection{O movimento decasségui ${ }^{1}$}

Em meados da década de 80, o Japão passou por um grande crescimento econômico devido às exportações principalmente para os Estados Unidos e Europa (TAKEDA e KUWAHARA, 2005) e ao mesmo tempo apresentou um grave problema de falta de mão de obra. Para suprir essa falta, o governo japonês iniciou uma campanha de recrutamento de estrangeiros para trabalhar no país. Como o Brasil é um país que possui uma grande população nikkei ${ }^{2}$, tornou-se um país com um alto índice de população que emigrou para aquele país. Esse processo migratório ficou conhecido como movimento decasségui, no qual de significa sair e kassegui trabalhar, no significado etimológico, trabalhar fora de seu lugar de origem. (ОКАMOTO, 2007).

COSTA (2007) sugere uma classificação cronológica da imigração brasileira ao Japão sugerida por Naoto Higuchi ${ }^{3}$, na qual o ponto de partida é o ano de 1980 e está dividida em cinco fases. A primeira fase (1980-1984) caracteriza-se por um reduzido numero de brasileiros, pois em sua maioria são cônjuges de japoneses que residiram muito tempo no Brasil; a segunda fase (1985-1989) tem como referencial a primeira publicação de oferta de emprego no Japão em um jornal japonês no Brasil. Isso se deve à queda da taxa de natalidade, o esgotamento dos processos de migração do campo para a zona urbana e o recrutamento de mulheres e idosos no arquipélago japonês. Isso tornava evidente a escassez de trabalhadores nativos. Assim, a solução encontrada foi a de reintegrar os imigrantes japoneses que estavam espalhados no Brasil, convocando-os para um retorno; a terceira fase (1990-1992) ocorreu com a mudança da Lei de Controle de Imigração que possibilitou o visto de trabalho para os isseis (imigrantes japoneses), os nisseis (filhos de imigrantes japoneses), os sanseis (netos de imigrantes japoneses) e seus cônjuges; a quarta fase (1993-1997) foi marcada pela recessão que marcou o Japão e a queda da produção industrial, afetando diretamente os trabalhos dos decasséguis e a última fase (1998) até a atualidade teve como marco a nova geração de decasséguis, na qual os sanseis superaram os nisseis nesse novo perfil de imigrante.

Apesar desses avanços que ocorreram na comunidade nikkei, como o surgimento de mercados, restaurantes, shoppings e clubes noturnos voltados para a comunidade brasileira, ainda existem vários problemas que cercam a vida desses trabalhadores, como o preconceito da

\footnotetext{
${ }^{1}$ A palavra foi incluída nos dicionários de Língua Portuguesa com a grafia "Decasségui”. O Dicionário eletrônico HOUAISS (2001) descreve o verbete do seguinte modo “adj.2g.s.2g. que ou aquele que se fixa temporariamente, no Japão, para trabalhar freq. como mão de obra direta. ETIM. jap. dekassegui 'trabalhador temporário' SIN/VAR decasségui.

${ }^{2}$ O termo nikkei, denomina na língua japonesa, os descendentes de japoneses nascidos fora do Japão e os japoneses que vivem regularmente no exterior.

${ }^{3}$ Professor do Departamento de Ciência Social da Universidade de Tokushima.
} 
sociedade japonesa com o nipo-brasileiro, o idioma japonês e a questão citada por COSTA (2007) com a educação dos filhos desses nipo-brasileiros.

O objetivo geral dessa pesquisa é investigar a constituição do projeto de vida dos decasséguis que retornaram ao Brasil. A partir disso, a pesquisa propõe compreender as perspectivas do projeto de vida dos decasséguis e sua constituição; levantar a qual país este projeto está vinculado e quais aspectos da vida (família, trabalho, estudos) estão envolvidos nesse projeto e investigar o planejamento e as ações realizadas pelo decasségui para a realização de tal projeto.

\section{METODOLOGIA}

A pesquisa qualitativa foi o norteador desse trabalho, utilizando o tipo de pesquisa exploratória-descritiva que consiste no aprofundamento e na compreensão do tema proposto em questão. A técnica utilizada para a coleta de dados foi a entrevista semidirigida.

A amostra foi composta por 04 decasséguis com idade entre 20 a 30 anos, de ambos os sexos (masculino e/ou feminino), solteiros e que tenham permanecido recentemente no Japão durante ao menos 02 anos. As entrevistas foram realizadas com 03 decasséguis do sexo masculino, com idades entre 25 e 26 anos e uma do sexo feminino, com 20 anos de idade. As entrevistas foram gravadas e transcritas na íntegra. Os dados estão em fase de análise, de acordo com a análise de conteúdo, levando em consideração as regularidades e peculiaridades dos discursos. A discussão e a interpretação dos dados serão realizadas de acordo com a teoria psicanalítica e os estudos interculturais. O campo escolhido para que ocorram as entrevistas foi o município de Araçatuba-SP, no qual existe uma grande comunidade nikkei.

Foi realizado um levantamento bibliográfico a respeito do movimento migratório decasségui e as dificuldades que vivenciadas durante o tempo de permanência no Japão, como forma de compreender a questão envolvida na pesquisa. Foram consultados livros, artigos, pesquisas em bancos de dados online e no portal dos Consulados do Japão e do Brasil.

Por fim, a pesquisa foi submetida ao Comitê de Ética em Pesquisa (CEP) da Faculdade de Ciências e Letras - UNESP/ Câmpus de Assis sendo aprovado (Protocolo 09960912.2.0000.5401). Ademais, foi entregue aos sujeitos da pesquisa o Termo de Consentimento Livre e Esclarecido (TCLE), em duas vias, no qual estão contemplados: a participação voluntária, a garantia da privacidade, os riscos da pesquisa bem como os objetivos da pesquisa. 


\section{RESULTADOS}

Os resultados obtidos através do levantamento bibliográfico realizado nesse período demonstrou a pouca produção científica em psicologia em todos os bancos de dados virtuais e bibliotecas referentes ao estudo sobre projeto de vida com decasséguis. Ressaltando que nessa pesquisa foram utilizadas as duas formas de escrita a anterior (dekassegui) e a atual (decasségui).

No entanto, foram encontrados estudos realizados sobre os decasséguis da seguinte forma: 02 livros, 04 teses, 08 dissertações, 19 artigos e 17 trabalhos apresentados em congressos, sendo que em sua maioria foram publicados a partir do ano de 1998 e compõem principalmente as áreas da Sociologia e da Geografia. As poucas pesquisas referentes ao decasségui na área da Psicologia são referentes às condições de trabalho desqualificado que podem gerar sintomas de depressão e doenças psicossomáticas além da implicação do movimento decasségui durante seu tempo de existência, nessas três décadas, para a constituição da identidade do trabalhador nipobrasileiro.

$\mathrm{Na}$ análise das entrevistas pode-se observar que o principal motivo da imigração ao Japão foi a questão financeira, focada no ganho rápido e uma boa remuneração financeira, que à época não era acessível no Brasil para a maior parte de sua população, além da falta de perspectiva futura no país de origem. Além disso, dois entrevistados relataram a falta de perspectivas no Brasil. HALL (2001) explica que as imigrações após a Segunda Guerra Mundial ocorreram por diversos motivos (pobreza, seca, fome, etc.). No caso do Brasil, pode se citar a divida externa acumulada pelo governo, os altos índices inflacionais e a instabilidade econômica.

O tempo de permanência no Japão foi de no mínimo 02 meses a no máximo 08 anos, sendo os entrevistados trabalharam em serviços de indústrias de peças automotivas e alimentícias. Eles relatam que alcançaram seus objetivos financeiros na terra do sol nascente, pois mesmo sem uma formação escolar de nível superior obtiveram um acumulo financeiro rápido devido a boa remuneração salarial dos serviços prestados naquele país. Entretanto tiveram dificuldades durante seus percursos, sendo as principais: o preconceito dos cidadãos japoneses aos decasséguis e a falta de domínio da língua japonesa.

Todos os entrevistados pretendem constituir seus projetos de vida no Brasil e apesar das críticas ao país de origem, esperam obter sucesso e consideram o país como sua terra natal. 0 principal foco dos projetos de vida dos entrevistados é o financeiro, ou seja, a obtenção de sucesso financeiro. Tal sucesso nem sempre está relacionado a uma profissão específica, mas principalmente ao empreendedorismo, uma vez que a principal preocupação refere-se ao 
financeiro. Um dos motivos que justificam tal procura pode ser a importância em auxiliar a família, que seria uma forma de gratidão a todos os sacrifícios realizados pelos pais. Em segundo plano, e a longo prazo, aparecem projetos relativos ao estudo, seguido pela constituição de vínculos e família.

\section{DISCUSSÃO}

A importância atribuída à questão financeira na vida dos entrevistados pode ser compreendida através da constituição do ideal do ego familiar de tais pessoas. O ideal do ego familiar faz parte de um organizador ${ }^{4}$ familiar, "uma formação coletiva, para a qual contribuem os psiquismos pessoais, que concentra um jogo de representações psíquicas especificas do familiar e um denominador comum de emoções frequentemente exaltadoras" (EIGUER, 1989, p.29). O conceito de organizador familiar nos remete ao aspecto simbólico da família, constituindo-se num diferenciador inconsciente que permite apontar um referencial e uma origem em comum aos indivíduos pertencentes a esse grupo. O acumulo financeiro, prioritário para os decasséguis está relacionado com o mesmo intuito que seus ancestrais vieram fazer no Brasil, isto é, esse objetivo foi passado aos filhos ou netos, qual manteve-se presente em todas as gerações das famílias nipobrasileiras (OKAMOTO, 2007).

Para as famílias nipo-brasileiras, fundadas pelos imigrantes japoneses, a luta pela realização do sucesso financeiro foi o principal objetivo que motivou a emigração e mesmo com o estabelecimento de tais famílias no Brasil, esse ideal nunca deixou de existir.

O baixo nível de escolaridade verificado dentre os entrevistados associado à falta de perspectiva de futuro no Brasil, nos leva a refletir a qual tipo de perspectiva tais entrevistados se referem. No momento da partida ao Japão, os entrevistados possuíam entre 16 e 19 anos de idade, e um deles é natural daquele arquipélago. Viveram durante alguns anos de sua juventude como trabalhadores em serviços que exigiam pouca qualificação profissional e utilizaram todo o dinheiro acumulado nesse período para abrir um negócio próprio ou auxiliar a família. Apenas dois entrevistados referem à busca por qualificação profissional após o retorno ao Brasil. Tais dados nos levam a refletir no futuro incerto que cerca os entrevistados, diante da pouca qualificação profissional, num mundo no qual tal aspecto é tão valorizado. Talvez seja por isso que referem que

\footnotetext{
${ }^{4} \mathrm{O}$ conceito de organizador refere-se principalmente à ideia de que durante a evolução do bebê, ocorrem momentos críticos nos quais há a convergência de várias linhas de desenvolvimento integradas e reestruturadas num nível de complexidade mais elevado que funcionará como apoio para o desenvolvimento de novas funções (SPITZ, 1993).
} 
o Japão continua como uma opção caso seus planos sejam frustrados. Ou seja, não descartam a possibilidade em retornar àquele país caso seja necessário acumular um ganho novamente.

Tais dados nos levam a apontar à importância da questão do hibridismo identitário na constituição de projetos de vida dos entrevistados. HALL (2001) define a identidade hibrida ou hibridismo, como uma das características fundamentais do sujeito pós-moderno. Um dos termos que compõem o hibridismo é a globalização em que são atravessadas as fronteiras nacionais havendo uma nova combinação de espaço-tempo, tornando o mundo, em realidade e em experiências, interconectado. Isso significa que apesar de apontarem o Brasil como sua terra natal, o Japão surge como um lugar seguro, organizado e no qual sentem segurança com relação ao ganho financeiro, ao contrário do seu país de origem. Tal questão também aponta para a importância da transmissão psíquica geracional, na qual, no imaginário familiar da maioria das famílias nipo-brasileiras, o Japão aparece como um local idealizado.

Porém, quando indagados a respeito do retorno ao Brasil, a maioria relata que o mesmo foi motivado devido à saudade e ao sofrimento causado devido à árdua rotina de trabalho caracterizado pelas extensas cargas horárias de serviço e ao preconceito da sociedade japonesa em relação aos imigrantes, perpassado pela falta de domínio do idioma japonês, que acaba dificultando uma relação de diálogo entre os decasséguis e os japoneses, que por sua vez retornam ao Brasil para se sentirem mais acolhidos.

Outro aspecto que podemos apontar relaciona-se os poucos estudos relacionados ao movimento decasségui na Psicologia, o que demonstra que o assunto ainda é pouco explorado. $A$ existência de pesquisas contribuiria para a compreensão de múltiplos aspectos desse processo imigratório que possui a duração de três décadas e poderia auxiliar em propostas de políticas públicas para a população emigrante que retorna ao Brasil com dificuldades de adaptação, de planejamento e expectativa para o futuro.

\section{CONCLUSÃO}

Conclui-se que para os decasséguis entrevistados, a importância do ganho financeiro surge como prioridade de vida, da mesma forma que as gerações anteriores das famílias nipobrasileiras. Apesar de verbalizarem o desejo de realizarem seus projetos de vida no Brasil, apontam que todos os projetos iniciados aqui não resultam no mesmo retorno financeiro que nas fábricas japonesas. Decorrente disso, o Japão aparece sempre como uma alternativa de retorno caso seus projetos fracassem e de certa forma, como um país mais viável com relação à 
concretização de seus planos. Porém, em nenhum momento, aspectos tais como escolaridade e qualificação profissional é analisada pelos entrevistados como um dos motivos de tais dificuldades. A única questão à qual se referem diz respeito à possibilidade de ganho financeiro rápido e diante disso, o Japão surge como a melhor alternativa.

Apesar de todo o sofrimento envolvido durante a permanência no Japão, os entrevistados consideram a experiência válida, mesmo que ainda não tenham atingido os objetivos traçados e apresentem dificuldades na vida social devido a todas as rupturas de vínculos vividos durante os anos que viveram temporariamente em outro país.

\section{REFERÊNCIAS BIBLIOGRÁFICAS}

ASARI, A. Y.; YOSHIOKA, R. O retorno dos migrantes trabalhadores nikkeis ao Brasil. Costa Rica: Revista Geográfica de América Central, 2011.

BELTRÃO, K. I.; SUGAHARA, S. Permanente temporário: dekasseguis brasileiros no Japão. São Paulo: Revista Brasileira de Estudos de População, 2006.

CASTRO, M. L. O fenômeno dekassegui: os trabalhadores nikkei brasileiros no Japão. São Paulo: São Paulo em Perspectiva, 1994.

COSTA, J. P. C. De decasségui a emigrante. Brasília: Fundação Alexandre Gusmão, 2007.

DANTAS, S. D. (org.). Diálogos interculturais: reflexões interdisciplinares e intervenções psicossociais. São Paulo: Instituto de Estudos Avançados da Universidade de São Paulo, 2012.

EIGUER, A. Um divã para a família: do modelo grupal à terapia familiar psicanalítica. Porto Alegre: Artes Médicas, 1989.

FREUD, S. Introdução ao narcisismo: ensaios de metapsicologia e outros textos (1914-1916)/ Sigmund Freud; tradução e notas Paulo César de Souza. São Paulo: Companhia das Letras, 2010.

GOMES, N. C. B. et al. Percepção da criança japonesa através dos tempos. Cuiabá: Revista eletrônica Documento Monumento, 2011.

HALL, S. A identidade cultural na pós-modernidade. Rio de Janeiro: DP\&A, 2001.

KOGA, S. T.; AMARAL, S. T. Ijime - o assédio moral no ambiente de trabalho do dekassegui. Presidente Prudente: ETIC - Encontro de Iniciação Científica, 2007. LOURENÇÃO, G. V.; MACHADO, I. J. R. A esgrima japonesa, ai (e) migração e os direitos humanos. Algumas considerações. Brasília: REMHU - Revista Interdisciplinar da Mobilidade Humana, 2008.

MIYASAKA, L. S. et. al. Migração e saúde mental: brasileiros descendentes de japoneses no Japão e no Brasil. São Paulo: Jornal Brasileiro de Psiquiatria, 2007. 
NOZAKI, I. A educação escolar das crianças brasileiras no Japão: os paradoxos da imigração.

Toronto: Congresso LASA - Associação de Estudos Latino-Americanos; 2010.

OKAMOTO, M. Y. Dekassegui e família: encontros e desencontros. Tese (Doutorado em Psicologia Clínica)-PUC/SP, São Paulo, 2007.

SASAKI, E. M. Um olhar sobre o movimento dekassegui de brasileiros ao Japão no balanço do centenário da Imigração Japonesa ao Brasil. São Paulo: Simpósio de Avaliação do Centenário da Imigração Japonesa no Brasil, 2009.

SPITZ, R. A. O primeiro ano de vida: um estudo psicanalítico do desenvolvimento normal e anômalo das relações objetais. São Paulo: Martins fontes, 1993.

TAKEDA, H.; KUWAHARA, M. Y. O papel do governo na retomada econômica japonesa. São Paulo: Revista Jovens Pesquisadores, 2005.

TONGU, E. A. S. Migrações, processo educacional e dekassegui: um estudo da rede de relações em torno da criança nikkei na escola brasileira no Japão. Tese (Doutorado em Educação)-USP/SP, São Paulo, 2010.

UENO, L. S. Migrantes em trânsito entre Brasil e Japão: uma intervenção psicossocial no retorno. Dissertação (Mestrado em Psicologia Social)-USP/SP, São Paulo, 2008.

WATANABE, A. F. A experiência das raízes e o dekassegui: um estudo em psicologia social a partir de reconstrução autobiográfica. Dissertação (Mestrado em Psicologia) USP/SP, São Paulo, 2008. 